\title{
Postoperative endophthalmitis due to Trichosporon cutaneum
}

\author{
HADI A. SHEIKH, S. MAHGOUB, AND K. BADI
}

From the Eye Hospital, Khartoum, and the Microbiology (Mycology) Department, Faculty of Medicine, University of Khartoum, Sudan

Postoperative mycotic endophthalmitis is not uncommon (Budek, I9I4; Fuchs, I9r9; Verhoeff, I924; Greetham and Makley, I957; Foster, Almeda, Littman, and Wilson, I958; Fine and Zimmerman, I959), and there has recently been a notable increase in the reports of such cases; only three cases were reported up to I957, but Theodore, Littman, and Almeda (I96I) reported eight cases in one calendar year, I958-1959. This may be due to a clearer understanding of the clinical picture and/or to the widespread use of antibiotics and steroids (Ley, I956; Tucker, I958; Fine and Zimmerman, 1959).

The diagnosis of postoperative fungal endophthalmitis, with rare exceptions, has been made on the clinical and histopathological evidence and not by culture. Trichosporon cutaneum has not hitherto been reported as a cause of endophthalmitis and has been recorded only once in a case of keratitis (Emmons, Binford, and Utz, I970). This paper describes two cases of postoperative infection with Trichosporon cutaneum which resulted in ocular degeneration, leading to loss of vision in one eye and enucleation of the other.

\section{Case reports}

Case I, a male Sudanese shop-keeper aged 70 years, underwent an intracapsular lens extraction in the right eye. On the second day after the operation he had a perforated peptic ulcer, and was transferred to a general surgical ward. However, 2 weeks after the operation, the eye was quiet, with a visual acuity of $6 / 12$ with a temporary aphakic correction. A fortnight later he presented with pain and redness of the same eye. Cells were seen in the anterior chamber and vitreous. He was given topical antibiotics and corticosteroids but no response was observed and a hypopyon developed. The anterior chamber was evacuated and the aspirate sent for culture. A few days later, the anterior chamber filled up again. When the diagnosis of a fungal infection was established he was given amphotericin B. The pain became less but the visual acuity gradually deteriorated to perception of light. For 6 months the condition remained quiet, but the eye became soft and finally vision was completely lost.

Case 2, a Sudanese housewife aged 65 years, had a right intracapsular lens extraction. The postoperative course was uneventful and the visual acuity was $6 / 9$ with correction. A month later mild iritis developed. This responded to systemic and local corticosteroid treatment, but 2 months later she had another attack of iritis which was slowly progressive and could not be checked by antibiotics or steroids. The anterior chamber became full of cells, clumps of fluffy deposits developed on the vitreous face, and hypopyon developed. The anterior chamber was evacuated and the contents sent for culture, but it soon filled up again. When the diagnosis of fungal infection was established Address for reprints: Dr. H. A. Sheikh, Department of Clinical Ophthalmology, Institute of Ophthalmology, Judd Street,
London, WC1H 9QS 
amphotericin B was given but without avail. The eye became injected, the cornea oedematous, and the tension very high. The vision deteriorated to no perception of light. The eye was extremely painful and ultimately had to be enucleated.

\section{Pathology}

The enucleated eye was sent to Professor Norman Ashton, Director of the Department f Pathology, Institute of Ophthalmology, London, who reported as follows:

Macroscopically a horizontal section of the eye (Figure) showed white fluffy deposits in the vitreous, particularly on the anterior surface and posteriorly. Smears from the fluffy masses showed macrophages, polymorphonuclear leucocytes, lymphocytes, and fibrinous strands. Smears stained with periodic acid-Schiff (PAS) and celestin blue showed aggregations of PAS-positive structures. GrocottGomori silver stain showed a few black filamentous structures and yeast-like bodies. Electron microscopy showed fragments of hyphae and oval bodies with typical fungal fragments lying inside and outside macrophages.

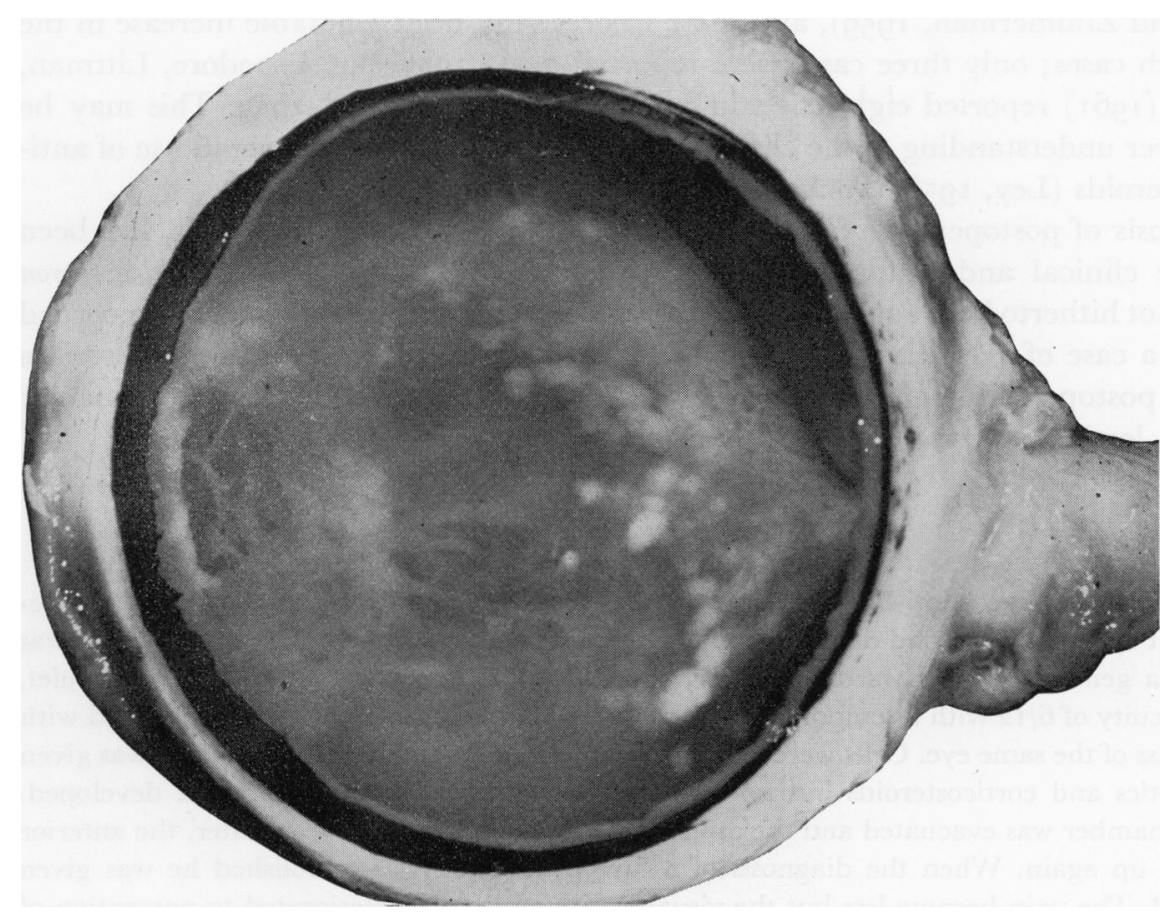

FIGURE Enucleated eye of Case 2 opened horizontally

Microscopical examination showed that all the layers of the eye were infiltrated with inflammatory cells, with a fibrinous cyclitic membrane containing pockets of pus in the anterior chamber, and aggregates of inflammatory cells in the vitreous. Inflammation of the retina was noticed more perivascularly and upon its surface. PAS-celestin blue stain showed numerous PAS-positive yeastlike bodies within the inflammatory tissue of the vitreous and the anterior chamber.

\section{Mycology}

The aspirates from both cases were cultured on 4 per cent. glucose peptone agar (Sabouraud's agar) and 4 per cent. malt extract agar. Culture bottles were incubated at both $26^{\circ}$ and $27^{\circ} \mathrm{C}$. Dull, white, wrinkled colonies with partly submerged edges started to appear 
after 3 days from both specimens. Growth was better at $26^{\circ} \mathrm{C}$. As the colony aged, the colour became creamy. Mounts in lactophenol cotton blue showed various shapes of circular, ovoid, and elongated cells in addition to mycelia. The cultures were sent to Dr. Phyllis Stockdale of the Commonwealth Mycological Institute, England, who gave the final diagnosis of Trichosporon cutaneum.

Sections from the second eye were studied for specific immunofluorescence against conjugates of Candida albicans, Fusarium solani, and Aspergillus fumigatus by Dr. Y. M. Glayton of the Mycology Department, St. John's Hospital for Diseases of the Skin, London, but all tests gave negative results. The fungal nature of the causative organism was also confirmed by this test.

\section{Discussion}

The introduction of fungi into the eye during operation may result in a serious endophthalmitis which presents a typical clinical picture (Fine and Zimmerman, 1959): late, exogenous, suppurative lesions which are usually fairly well localized and respond to therapy initially, but exacerbation and progression follow.

Our first patient showed a generalized lesion from the start with no initial response to therapy. Lowered resistance after his peptic trouble may explain this deviation from the typical syndrome.

The clinical picture of the second patient was typical. At the start the lesion was clinically localized to the anterior segment, but with time the inflammatory process extended backwards into the vitreous. (This can be seen clearly in the hemisection of the eye.) The glaucoma which developed fits well with what Jones, Jones, Lim, Bron, Morgan, and Clayton ( 1969) and Jones, Jones, and Richards ( 1969 ) called "fungus-induced malignant aphakic glaucoma".

Both patients received antibiotics and steroids which may have decreased their resistance and/or increased the virulence of the fungus. The ineffectual treatment with amphotericin $\mathrm{B}$ may be due to the late start of treatment or to the fact that the fungus was not sensitive to the drug. Tests of sensitivity in vitro were not done.

The diagnosis of fungal infection was suspected from the clinical picture. Anterior chamber aspirate culture confirmed the diagnosis and enabled the causative organism to be identified. Trichosporon cutaneum has been reported both as a pathogen and a saprophyte. Lodder (197I) gives the sources of species studied as: skin infection, wood pulp, soil, lake and river water, animal excreta, sewage, and orange peel. Its virulence to man is minimal but in conditions such as these it becomes a typical opportunist organism.

\section{Summary}

Two instances are described of fungal endophthalmitis after cataract surgery. Anterior chamber aspirate in each case proved the causative fungus to be Trichosporon cutaneum. This organism, which is known to be a fungus of minimal virulence to man, was responsible for serious endophthalmitis which led to phthisis bulbi in one case, and loss of vision, severe pain, and enucleation in the second. In both cases the infection was possibly aggravated by the use of antibiotics and steroids. The histopathology of the enucleated eye is described.

Our thanks are extended to Prof. N. Ashton of the Institute of Ophthalmology, London, for the histopathological studies, to Dr. Y. M. Glayton of the Department of Mycology, St. John's Hospital for 
Diseases of the Skin, for her efforts to identify the causative organism by immunofluorescence, to Doctor Phyllis Stockdale of the Commonwealth Mycological Institute, England, for making the final identification of the fungus, and to Mr. J. H. Dobree for his valuable advice and criticism.

\section{References}

BUDEK, R. (1914) Prag. med. Wschr., 39, 87

Emmons, c. W., BINFORD, c. H., and UTz, J. P. (1970) "Medical Mycology". Lea and Febiger, Philadelphia

fine, B. s., and zimmerman, L. E. (1959) Amer. F. Ophthal., 48, I $5 \mathrm{I}$

Foster, J. B. T., Almeda, E., Littman, M. L., and wilson, M. E. (1958) A.M.A. Arch. Ophthal., 6o, 555 FUCHS, E. (1919) v. Graefes Arch. Ophthal., IOI, 24

GReetham, J. S., and makley, T. A. (1957) A.M.A. Arch. Ophthal. 58, 558

JONES, B. R., JONES, D. R., LIM, A., BRON, A. J., MORGAN, G., and GLAYTON, Y. M. (I969) Trans. ophthal. Soc. U.K., 89, 757

$\longrightarrow$,

LEY, A. P. (1956) Amer. F. Ophthal., 42, no. 4 (Oct.) pt II, p. 59

LODDER, J. (1971) "The Yeasts , a Taxonomic Study", 2nd ed. North Holland Publishing Company,

Amsterdam

theodore, F. H., Littman, M. L., and Almeda, e. (196I) Arch. Ophthal. (Chicago), 66, i63

TUCKer, D. P. (1958) New Engl. F. Med., 258, 946

VERHOEFF, F. H. (1924) Arch. Ophthal. (N.Y.), 53, $5^{1} 7$ 